\title{
Um Povo para todos os Povos: elementos introdutórios à eclesiologia trinitária de Lesslie Newbigin ${ }^{1}$
}

\author{
A People for all People: \\ introductory elements to Lesslie Newbigin's Trinitarian \\ ecclesiology
}

Gladson Pereira da Cunha

\section{Resumo}

Refletir sobre a Igreja é também refletir sobre a sua missão. Para Lesslie Newbigin a reflexão sobre a Igreja exigia também o estudo e a compreensão da missão do Deus Uno e Trino. O objetivo deste artigo é apresentar, ainda que de maneira introdutória, os principais aspectos da proposta eclesiológica feita por Lesslie Newbigin. Para Newbigin, a Igreja é missionária, enquanto ela dá continuidade a missão do Deus Trino e Uno - Pai, Filho e Espírito Santo - assumindo cada uma das pessoas como referência para determinada parte da sua ação. A Igreja assume em seu agir as virtudes teologais - fé, esperança e amor - como orientadora de cada aspecto do agir. Na experiência da missão do Deus Trino e Uno, a Igreja é o povo de Deus chamado para o testemunho do agir salvador da Trindade na história das pessoas, sendo ela própria, a demonstração visível dessa salvação. A Igreja, portanto, se amolda a missão da Trindade.

Palavras-chave: Newbigin. Igreja. Missão. Trindade.

\footnotetext{
${ }^{1}$ Este artigo tem como base o que construímos na nossa tese de doutorado: CUNHA, G., Não os tires do mundo: Estudo da relação Igreja-Mundo numa denominação presbiteriana brasileira, à luz da reflexão teológica de Lesslie Newbigin e José Comblin, defendida, em 29 de agosto de 2019, no Programa de Pós-Graduação em Teologia da PUC-Rio. Esta tese contou com subsídio da CAPES, Código de Financiamento 001.
} 


\begin{abstract}
The reflection on the Church is also to reflect on its mission. For Lesslie Newbigin, to reflect on the Church also required the study and understanding of the mission of the One and Triune God. The purpose of this paper is to present, albeit in an introductory way, the main aspects of the ecclesiological proposal made by Lesslie Newbigin. For Newbigin, the Church is missionary, while she continues the mission of the One and Triune God - Father, Son, and Holy Spirit - assuming each person as a reference for a certain part of her action. The Church assumes in her action the theological virtues - faith, hope, and love - as a guide for every aspect of the action. In the experience of the mission of the One and Triune God, the Church is the people of God called to witness to the saving action of the Trinity in the history of the people, being itself the visible demonstration of that salvation. The Church, therefore, shapes the mission of the Trinity.
\end{abstract}

Keyword: Newbigin. Church. Mission. Trinity.

\title{
Introdução
}

“A Igreja peregrina é, por sua natureza, missionária, visto que tem a sua origem, segundo o desígnio de Deus Pai, na missão do Filho e do Espírito Santo". ${ }^{2}$ Estas palavras identificam o tom para se compreender o sentido da Igreja não apenas para o catolicismo, mas para todas as demais tradições cristãs. De alguma maneira, a busca por uma identidade para a Igreja no pós-guerra, conduziu não apenas os padres conciliares católicos como também teólogos protestantes ao mesmo resultado: ela é missionária. ${ }^{3}$

Esse novo entendimento acerca da Igreja foi fruto da busca pelo entendimento do seu papel na história do mundo. Um mundo atordoado por duas grandes guerras, dominado pelo desejo de autonomia, com radicais transformações socioculturais e filosóficas. Além disso, os avanços científicos pareciam reduzir a necessidade de um Pai, de um Deus. A secularização aparentava ser a nova forma de religiosidade, aplaudida e ansiada pelos homens da

\footnotetext{
${ }^{2}$ AG 2.

${ }^{3}$ BLAUW, J., A Natureza Missionária da Igreja, p. 120-126.
} 
teologia. ${ }^{4}$ Qual deveria ser o papel da Igreja cristã nesse contexto? Qual a sua função para esse admirável mundo novo? Como deveria agir nessa nova realidade?

O objetivo deste artigo é apresentar, de maneira introdutória, a eclesiologia proposta por Lesslie Newbigin, demonstrando como ele respondeu às perguntas feitas anteriormente. Para Newbigin, a Igreja é missionária e, em sua missão, ela dá continuidade a missão do Deus Triúno - Pai, Filho e Espírito Santo - assumindo cada uma das pessoas como referência para determinada parte da sua ação. Dito isto, este texto apresentará uma visão geral da eclesiologia tal como pensada por Newbigin, destacando sua característica missionária. Em seguida, apresentar-se-á a dimensão trinitária da Igreja, conforme o autor.

\section{Notas biográficas de Newbigin}

James Edward Lesslie Newbigin (1909-1998) foi um clérigo, teólogo, missiólogo e missionário inglês. De origem escocesa, a família Newbigin era tradicionalmente ligada à Igreja da Escócia (presbiteriana). Graduou-se em Geografia no Queen's College, em Cambridge. Ligado ao Students Chistians Movement (SCM), ${ }^{5}$ teve contato com nomes importantes do Conselho Internacional de Missões (CIM), que o influenciaram na opção por se tornar missionário no subcontinente indiano. Estudou teologia no Westminster College, também em Cambridge. Em 1936, foi ordenado e enviado como missionário pela Igreja da Escócia. Em 1947, participou da organização da Igreja do Sul da Índia ${ }^{6}$, uma denominação criada a partir da unificação de diversas missões protestantes - anglicanos, presbiterianos, congregacionais e metodistas - da qual Lesslie Newbigin se tornou um dos primeiros bispos. Com participação efetiva no CIM, Newbigin foi eleito seu Secretário-Geral de 1959 até a sua fusão com o Conselho Mundial de Igrejas (CMI), em 1961. Permaneceu como diretor da divisão de Missão Mundial e Evangelismo do CMI até 1964. Retornou a Índia, onde permaneceu a frente da diocese de Madras, da CSI, até 1974, quando se aposentou e retornou a Inglaterra.

\footnotetext{
${ }^{4}$ COX, H., A Cidade do Homem, p. 27-31. O próprio Newbigin seria influenciado pela ideia da secularização, vindo a perceber posteriormente, mais os seus riscos que suas vantagens.

${ }^{5}$ WAINWRIGHT, G., Lesslie Newbigin, p. 4.

${ }^{6}$ Em língua inglesa, o nome dessa denominação é Church of South India, doravante em referências a essa denominação será usada a sigla CSI.
} 
Em seu país natal, Newbigin se filiou a The United Reformed Church, uma denominação fruto da unificação entre presbiterianos ingleses e congregacionais galeses, tornando-se seu moderador entre 1978 e 1979. ${ }^{7}$ Além disso, Newbigin lecionou no Oak Selly Colleges, ligado à Universidade de Birmingham. ${ }^{8}$ Em 1989, Newbigin se afastou em definitivo das funções ministeriais e educacionais se recolhendo para o merecido descanso. Faleceu em 30 de janeiro de 1998.

A produção literária de Lesslie Newbigin é extensa, sendo composta por comentários bíblicos, ensaios, artigos e livros, tendo como objeto principal a missão cristã. ${ }^{9}$ De maneira geral, Newbigin construiu uma missiologia com forte ênfase bíblica e empírica, uma vez que ele não era apenas um teórico, mas experimentou as demandas e exigências próprias da comunicação missionária intercultural. Isso contribuiu em muito para a formulação da necessidade de uma nova evangelização do Ocidente.

Para Newbigin, a cultura ocidental havia se tornado uma espécie de campo missionário. ${ }^{10}$ Não se tratava apenas das consequências do processo de secularização que essa região enfrentou, mas a transformação da cultura ocidental numa cultura pagã e idolátrica, isto é, uma nova mentalidade que não negava simplesmente a existência de Deus, mas que estabeleceu uma nova divindade, o cientificismo pós-iluminista. ${ }^{11}$

A perspectiva teo-missiológica newbiginiana tem como fundamento a

\footnotetext{
${ }^{7}$ WAINWRIGHT, G., Lesslie Newbigin, p. 14.

${ }^{8}$ O Selly Oak Colleges foi organizado em 1906, por um grupo Quaker, e incluía as seguintes faculdades: Kingsmead (Metodista); St. Andrews Hall (Presbyterian/Batista/Congregacional); Crowther Hall e College of the Ascension (Anglicanos); Overdale (Igreja de Cristo); Woodbrooke (Quaker). Com o passar dos anos e com poucas vocações, o custo de manutenção do Selly Oak tornou-se caro e deficitário o que levou ao fim da federação de Selly Oak. O'CONNOR, D., All change at Selly Oak; MOSLEY, A. Kingsmead 1969-77.

${ }^{9}$ Um exemplo do impacto do pensamento de Newbigin é a sua influência sobre a missiologia de David Bosch. Em Missão Transformadora, de 1991, Bosch fez várias referências a Newbigin e seus trabalhos. Ao que tudo indica havia até mesmo uma amizade intelectual e simpatia entre ambos. Prova disso, foi a consideração feita por Newbigin, por meio da qual descrevia a obra de Bosch como uma "espécie de Summa Missiologica...", uma clara alusão a Summa Theologica, a opera magna de Tomás de Aquino. Segundo Newbigin, o livro de Bosch se tornaria uma "base indispensável para o ensino da missiologia por muitos anos". BOSCH, D. J., Transforming Mission, (contracapa). No entanto, a demonstração dessa influência desviaria dos objetivos propostos para este artigo.

${ }^{10}$ NEWBIGIN, L., Foolishness to the Greeks, p. 1.

${ }^{11}$ NEWBIGIN, L., Foolishness to the Greeks, p. 21-41; NEWBIGIN, L., A Religião do Homem Secular, p. 58-59.
} 
ação do Deus Uno e Trino na história da sua criação. ${ }^{12}$ Para Newbigin, não é possível anunciar o Evangelho sem fazer referência a Trindade..$^{13}$ Deste ponto, temas como a eleição de um povo para comunicar essa mensagem em palavras e ação se torna algo que determinará ao longo de toda a história universal a existência de um grupo de pessoas que vive em função dos demais para testemunhar as ações salvíficas do Deus Uno e Trino. ${ }^{14}$ A Igreja é, portanto, o novo povo de Deus Uno e Trino, que, se movimenta por entre as nações da terra, tem o papel de abençoá-las da mesma maneira que cumpria esse papel o patriarca Abraão (Gn 12,3). ${ }^{15}$

\section{Notas gerais da eclesiologia Newbigin}

A Igreja é uma consequência natural ao ministério de Jesus Cristo. Afinal, foi ele quem a edificou e a tem, constantemente, edificada (Mt 16,18). Embora, em O Evangelho em uma Sociedade Pluralista, Newbigin não faça uma exposição do conceito Igreja, tudo o que diz respeito a esse tema tem lugar em obras anteriores. O Evangelho em uma Sociedade Pluralista é uma obra final, que se sustenta sobre alicerces anteriormente lançados pelo fazer teológico de Newbigin, os quais têm a Igreja e Missão como temas centrais.

De acordo com o teólogo dinamarquês Jeppe Nicolajsen, Newbigin fez duas importantes contribuições para a missiologia. ${ }^{16}$ A primeira está relacionada aos seus primeiros escritos, anteriores a 1974, entre os quais se encontra Household of God. De acordo com Nicolajsen, esses escritos desempenharam um papel significativo no desenvolvimento de uma eclesiologia missional. A outra contribuição tem a ver com os escritos de Newbigin posteriores a 1974 até 1998, ano de sua morte. Nessa segunda fase, os escritos do bispo Newbigin contribuíram para o desenvolvimento de uma missiologia da cultura ocidental, que como Nicolajsen enfatiza, é a consciência newbiginiana que o mundo ocidental pós-Cristandade se tornou um campo missionário. ${ }^{17}$

\footnotetext{
${ }^{12}$ NEWBIGIN, L., Foolishness to the Greeks, p. 40.

${ }^{13}$ NEWBIGIN, L., The Mission of Triune God, p. 15.

${ }^{14}$ NEWBIGIN, L., The Open Secret, p. 79.

${ }^{15}$ NEWBIGIN, L., The Open Secret, p. 79.

${ }^{16}$ NICOLAJSEN, J. B., Beyond Christendom, p. 366; NIKOLAJSEN, J. B., Missional ekklesiologi, p. 19-23.

${ }^{17}$ NICOLAJSEN, J. B., Beyond Christendom, p. 363-380.
} 
A Igreja é o cordão dourado da teologia de Newbigin. ${ }^{18}$ Aliás, foi com esse tema que ele começou a desenvolver sua teologia missional. Para ele, o modo de existir da Igreja dentro dos seus diversos contextos está intrinsecamente relacionado com a proclamação do Evangelho de Jesus Cristo, que, em última análise, é o segredo revelado acerca da missão de Deus, isto é, o anúncio de todos os atos salvíficos de Deus para a salvação da humanidade e de toda a criação. Neste ponto é importante recuperar a noção de David Bosch acerca da missio Dei. ${ }^{19}$

Para Bosch a missio Dei era como a recuperação de um entendimento abandonado, uma vez que, para a igreja primitiva, a missão era uma intrínseca relação entre a cristologia, a soteriologia e a doutrina da Trindade. ${ }^{20}$ Deus ser um missionário era basicamente um atributo divino. ${ }^{21} \mathrm{Na}$ verdade, o conceito de missio Dei de Bosch é o mesmo que o utilizado por Newbigin, que foi um dos consolidadores da noção, como o próprio Bosch demonstrou. ${ }^{22}$

É dessa missão que a Igreja participa como continuadora da missão de Jesus. O ápice do seu ministério terreno, embora envolto em frustração, derrota e grande ignomínia, foi a cruz. Porém, é nessa mesma cruz, que todo o sentido do Evangelho ganha força e significado, Newbigin resume isso nos seguintes termos:

Segundo o testemunho do Novo Testamento, a cruz é o lugar aonde o reino de Deus se manifesta, aos olhos da fé, no que parece ser sua derrota; o poder de Deus na fraqueza; a sabedoria de Deus, na loucura. A fé pela qual a Igreja vive é que nesse acontecimento todo o quadro de coisas foi irreversivelmente mudado e que este é o lugar onde o significado do anúncio original do Evangelho é revelado: o Reino de Deus se aproximou. A Igreja pode manter e viver por esta fé porque este Jesus, crucificado em fraqueza, foi "designado Filho de Deus em poder segundo o Espírito de santidade pela ressurreição dos mortos" $(\mathrm{Rm} 1,4) .{ }^{23}$ (Tradução nossa)

\footnotetext{
${ }^{18}$ VANDERVELDE, G., The Church as Missionary Community, p. 10 Apud NICOLAJSEN, J. B., The Distinctive Identity of the Church, p. 23.

${ }^{19}$ BOSCH, D., Missão Transformadora, p. 466-470.

${ }^{20} \mathrm{BOSCH}$, D., Missão Transformadora, p. 467.

${ }^{21}$ BOSCH, D., Missão Transformadora, p. 468.

${ }^{22}$ BOSCH, D., Missão Transformadora, p. 445. Bosch faz referência ao texto: NEWBIGIN, L., One Body, One Gospel, One World.

${ }^{23}$ NEWBIGIN, L., The Open Secret, p. 49.
} 
Ao manter, viver e anunciar a fé no Crucificado-Ressuscitado, a Igreja assume a tarefa evangelizadora, que indica não mais a proximidade do Reino, mas a sua presença de fato, em sua ação transformadora da história. Agora é preciso que seja explicado como Newbigin entende a Igreja.

Em Household of God, Newbigin trabalhou a natureza da Igreja. O ponto-de-partida de sua reflexão foi contextual. Para ele, o rompimento de uma união existente entre Evangelho e cultura no Ocidente, as experiências das missões cristãs em terras estrangeiras e o movimento ecumênico, ofereciam uma forte base para se repensar a natureza da igreja cristã. Acerca disso bem esclarece Goheen:

Três fatores contribuíram para esse interesse ressurgente (acerca da natureza da Igreja). O primeiro foi o colapso do corpus Christianum. A cristandade foi o pano de fundo de todas as eclesiologias da Reforma. Essas eclesiologias da cristandade formularam sua compreensão da igreja em oposição umas às outras, e não no contexto de seu chamado em um ambiente não-cristão. A dissolução da cristandade trouxe uma crise para todas as eclesiologias enquadradas em suas suposições. $\mathrm{O}$ segundo fator que obrigou a repensar a natureza da igreja foi a missão cristã e o surgimento de igrejas não-ocidentais. O novo cenário dos ambientes pagãos, onde as novas igrejas estavam florescendo, exigiu uma reformulação das eclesiologias formadas em um cenário ocidental. [...] O terceiro fator que colocou a eclesiologia no centro da agenda teológica foi o surgimento do movimento ecumênico. Conforme as igrejas entravam em contato umas com as outras, elas reconheciam umas às outras como igrejas em algum sentido. ${ }^{24}$ (Tradução nossa)

Assim, Newbigin inicia a sua reflexão identificando em três diferentes eclesiologias, a possibilidade de resposta à questão da natureza da Igreja ${ }^{25} \mathrm{As}$ diferentes eclesiologias que o bispo Newbigin são naturalmente a protestante, a católica e a nascente eclesiologia pentecostal. ${ }^{26}$ Sobre isso comenta Goheen:

As duas primeiras respostas tradicionais foram incorporadas em duas das grandes tradições cristãs da história da igreja. A resposta protestante é que somos incorporados em Cristo através da fé no evangelho. A resposta católica é que somos incorporados à igreja historicamente contínua,

\footnotetext{
${ }^{24}$ GOHEEN, M. W., "As the Father has Send Me, I Am Sending You", p. 54-55.

${ }^{25}$ GOHEEN, M. W., "As the Father has Send Me, I Am Sending You”, p. 55.

${ }^{26}$ NEWBIGIN, L., La Familia de Dios, p. 123.
} 
institucionalmente unida e visível pela participação sacramental. A terceira resposta à pergunta vem de uma tradição de safra mais recente. Hesitando em nomeá-lo, Newbigin finalmente usa o termo pentecostal. Essa tradição responde à pergunta de que somos incorporados na igreja ao receber o Espírito Santo. Newbigin sustenta que nenhuma dessas tradições responde adequadamente à questão porque elas contrastaram essas três respostas bíblicas de maneiras mutuamente exclusivas. Cada uma das respostas domina uma tradição particular, e surgem distorções quando uma dessas respostas é considerada a única pista fundamental para a natureza da igreja. ${ }^{27}$ (Tradução nossa)

Em cada uma dessas eclesiologias Newbigin enfocaria uma das pessoas da Divindade, dando assim início a perspectiva trinitária de sua eclesiologia e, posteriormente, à sua teologia, como foi visto até aqui - considerar: A Igreja Missionária no Mundo moderno (1960-1969), The Open Secret (1978), Foolishness of the Greeks (1986), entre outras obras. Assim, como a Igreja presta um serviço de continuidade da missio trinitatis Dei, ela também assume as características da ação particular de cada uma das Pessoas divinas.

\section{Igreja como Congregação dos Fiéis: Deus Pai}

A primeira característica é que a Igreja é a Congregação dos Fiéis. O anúncio central da Boa-Nova proclamada por Jesus de Nazaré era um convite à participação no Reino de Deus Pai - e sobre essa ideia Newbigin deu muita ênfase. Receber e participar do Reino de Deus era aceitar, pela fé, a totalidade de sua presença em Jesus Cristo. Era crer nos eventos da morte e ressureição do Nazareno, mas também no seu envio da parte de Deus. Newbigin resume essa dinâmica nas seguintes palavras:

Quando perguntaram a Jesus: "Quais são as obras de Deus"? Jesus respondeu, segundo a afirmação de João: "A obra de Deus é esta: que creiais naquele que por ele foi enviado" (Jo 6,28-29). O mesmo Evangelho afirma que, crer nele é ter a vida eterna (Jo 17,3). No livro de Atos, referindo-se aos cristãos, fala-se dele como os que creram. Os apóstolos disseram ao carcereiro de Filipos: "Crê no Senhor Jesus e serás salvo" (At 16,31). E esta expressão poderia ser considerada como um sumário daquilo que se dizia a todos. Não é necessário apresentar muitos exemplos,

${ }^{27}$ GOHEEN, M. W., “As the Father has Send Me, I Am Sending You”, p. 54-55. 
basta recordar que, no Novo Testamento, quando se fala da nossa relação com Cristo, quando se trata de pontos essenciais (da fé cristã), se faz uso dos termos crer e fé. ${ }^{28}$ (Tradução nossa)

É nesse ponto, que Newbigin lança mão da eclesiologia protestante. De maneira geral, o conceito eclesiológico protestante assume que o pertencimento à Igreja se faz por meio da fé, uma vez que essa participação está diretamente relacionada com as doutrinas da salvação, mais especificamente, a justificação pela fé. ${ }^{29}$

Newbigin contrasta o Antigo e Novo Testamento, demonstrando que a participação na aliança com Deus se dava, inicialmente, pelo rito da circuncisão, porém, a partir de Jesus, a fé assume o seu lugar. Baseando-se no caso da conversão de Cornélio (At 10), demonstra que não pode haver salvação apegando-se às ações humanas, de modo que "existe apenas uma certeza da salvação: Cremos que pela graça do Senhor Jesus seremos salvos. O modo Divino de salvação é por graça, mediante a fé". ${ }^{30}$ Desta forma, ele demonstrou

${ }^{28}$ NEWBIGIN, L., La Familia de Dios, p. 44-45.

${ }^{29}$ STRONG, A. H., Teologia Sistemática, p. 635; GRUDEM, W., Teologia Sistemática, p.715717; CFW XXV,1-2: “A Igreja Católica ou Universal, que é invisível, consta do número total dos eleitos que já foram, dos que agora são e dos que ainda serão reunidos em um só corpo sob Cristo, seu cabeça; ela é a esposa, o corpo, a plenitude daquele que cumpre tudo em todas as coisas. A Igreja Visível, que também é católica ou universal sob o Evangelho (não sendo restrita a uma nação, como antes sob a Lei) consta de todos aqueles que pelo mundo inteiro professam a verdadeira religião, juntamente com seus filhos; é o Reino do Senhor Jesus, a casa e família de Deus, fora da qual não há possibilidade ordinária de salvação". Comentado a CFW, Dixhoorn interpretou: "Mais amplamente concebida, a Igreja "Católica", o que significa a Igreja "Universal", consiste de todo o povo de Deus - todos os que ele escolheu ou elegeu para salvar. Ela inclui aqueles que "já foram, que agora são e dos que ainda serão reunidos" como um só, sob Cristo (DIXHOORN, C., Guia de Estudo Confissão de Fé Westminster, p. 343).

${ }^{30}$ NEWBIGIN, L., La Familia de Dios, p. 48. Deve-se ter em mente que o contexto em Newbigin está trabalhando. Ele está no período pré-Conciliar, tempo de fechamento para o diálogo entre Protestantes e Católicos. E muito tempo antes da Declaração conjunta sobre a Doutrina da Justificação, em que luteranos e católicos afirmam: "Confessamos juntos que o pecador é justificado pela fé na ação salvífica de Deus em Cristo; essa salvação lhe é presenteada pelo Espírito Santo no batismo como fundamento de toda a sua vida cristã. Na fé justificadora o ser humano confia na promessa graciosa de Deus; nessa fé estão compreendidos a esperança em Deus e o amor a Ele. Essa fé atua pelo amor; por isso o cristão não pode e não deve ficar sem obras. Mas tudo o que, no ser humano, precede ou se segue ao livre presente da fé não é fundamento da justificação nem a faz merecer”. Portanto, deve-se levar em consideração a ideia que ele está propondo de uma eclesiologia que unifica as três eclesiologias e não uma crítica as igrejas que a adotam. IGREJA CATÓLICA APOSTÓLICA ROMANA; FEDERAÇÃO LUTERANA MUNDIAL, Declaração conjunta sobre a Doutrina da Justificação. 
que fé e crer são a exigência central para participação na comunidade cristã. Esta fé era acolhida, segundo Newbigin, porque a Igreja nascente entendia que a fé marcava a regeneração promovida pelo Espírito Santo, que era, analogicamente, a circuncisão do coração $(\mathrm{Cl} 2,11-12)$. Mas, em que esse entendimento contribui para a definição da natureza da Igreja? A resposta é simples. Para o bispo de Madras, a natureza constituinte da Igreja é a fé daqueles que assumem o seguimento de Jesus, que se concretiza na vida pessoal e comunitária daqueles que se reúnem como discípulas e discípulos de Cristo. Neste ponto, Newbigin critica a eclesiologia protestante construída sob a base de uma Igreja Invisível, totalmente espiritual, direta e absolutamente ligada à fé, num sentido abstrato e que, por isso, não pode ser vista. Há, portanto, uma dimensão visível da Igreja em que essa fé deve ser concretizada.

\section{Igreja como o Corpo de Cristo}

A segunda característica é de natureza cristológica, uma vez que a Igreja é designada como o Corpo de Cristo. Nesse caso, o Corpo de Cristo não deve ser entendido numa estrutura mística, metafísica, ideal ou mesmo dentro de uma relação dualista, mas como algo inteiramente visível e imanente. ${ }^{31}$ Para Lesslie Newbigin, a "incorporação em Jesus Cristo é primária e essencialmente por meio da incorporação sacramental em sua Igreja", ${ }^{2}$ afinal de contas, "ser batizado é ser incorporado a morte de Jesus de modo a tornar-se participante da sua vida ressurreta e, assim, compartilhar sua missão contínua ao mundo. É ser batizado em sua missão". ${ }^{33}$ Evidentemente, esse batismo é a apropriação pela fé da graça concedida em Jesus. ${ }^{34}$ Nessa característica existem duas lógicas: a da Eleição e a da Missão.

Como membro da tradição reformada, Newbigin não negava a doutrina da Eleição ou a também chamada Predestinação, ${ }^{35}$ aliás, esse tema é algo rei-

\footnotetext{
${ }^{31}$ NEWBIGIN, L., La Familia de Dios, p. 90.

${ }^{32}$ NEWBIGIN, L., La Familia de Dios, pp.84-85.

${ }^{33}$ NEWBIGIN, L., O Evangelho em uma Sociedade Pluralista, p. 157.

${ }^{34}$ NEWBIGIN, L., La Familia de Dios, p.51

${ }^{35}$ Como sua base é presbiteriana, o seu ponto-de-partida são as afirmações da CFW III,1-4, que afirma: "I. Desde toda a eternidade, Deus, pelo muito sábio e santo conselho da sua própria vontade, ordenou livre e inalteravelmente tudo quanto acontece, porém de modo que nem Deus é o autor do pecado, nem violentada é a vontade da criatura, nem é tirada a liberdade ou contingência das causas secundárias, antes estabelecidas. II. Ainda que Deus sabe tudo quanto pode ou há de acontecer em todas as circunstâncias imagináveis, ele não decreta coisa alguma por
} 
terado em suas obras. ${ }^{36}$ Porém, antes de assumir a postura conservadora dos Símbolos de Westminster, uma construção em relação opositiva-excludente entre os "salvos" e os "não-salvos", Newbigin observa o todo das narrativas bíblicas, que, segundo ele, apontam para "um povo escolhido", com o qual Deus trabalha para a salvação dos demais povos. Israel, enquanto nação, observa Newbigin, possuía um caráter de povo-missionário, por ser o povo-escolhido. Acerca disso, Newbigin escreve:

Deus, de acordo com a Bíblia, propôs a salvação de todos: "Ele deseja que todos os homens sejam salvos e cheguem ao conhecimento da verdade" $(1 \mathrm{Tm} 2,4)$. A sua primordial aliança é para abençoar a todos, sem condições, e inclui a bênção da criação pela humanidade (Gn 9,1-17). Entretanto, quando os seres humanos perderam essa bênção, por causa do seu imperialismo autoconfiante (Gn 11,1-9), Deus escolheu uma das famílias da humanidade para ser portadora da bênção em favor de todos (Gn 12,13). Esta família não é, de forma alguma, superior ao resto da raça humana. As histórias antigas repetidamente enfatizam que a conduta "pagã" é mais nobre e justa do que a dos eleitos. Alguém poderia citar, por exemplo, a conduta contrastante de Abraão e Faraó (Gn 12,10-20), de Isaque e Abimeleque (Gn 26,1-11), de Jacó e Esaú (Gn 27 com Gn 33), e a história de Jonas [...]. Mas, o Antigo Testamento retrata repetidamente o povo escolhido como caindo na ilusão de que eles têm uma posição privilegiada com Deus que os assegura contra o desastre. Através dos repetidos golpes de martelo da derrota, destruição e deportação, interpretados pelos fiéis profetas, Israel tem que aprender que a eleição não é para conforto e segurança, mas para o sofrimento e humilhação. Como o golpe segue, surge a repetida tentação de pensar que Deus esqueceu sua aliança e abandonou seu povo. Mas, de novo e de novo, há um chamado profético para reconhecer a mão de Deus, que nunca cancelará sua aliança, mas cujo propósito inabalável é que Israel seja sua testemunha, que manifesta sua soberana glória à todas as nações. A eleição de Israel significa que ela é chamada para ser serva e testemunha do Senhor para todas as nações,

\footnotetext{
havê-la previsto como futura, ou como coisa que havia de acontecer em tais e tais condições. III. Pelo decreto de Deus e para manifestação da sua glória, alguns homens e alguns anjos são predestinados para a vida eterna e outros preordenados para a morte eterna. IV. Esses homens e esses anjos, assim predestinados e preordenados, são particular e imutavelmente designados; o seu número é tão certo e definido, que não pode ser nem aumentado nem diminuído".

${ }^{36}$ NEWBIGIN, L., La Familia de Dios, p. 141-144; NEWBIGIN, L., The Open Secret, p. 17-18; NEWBIGIN, L., O Evangelho em uma Sociedade Pluralista, p. 111-121.
} 
não para ser governante das nações. Ser eleito é uma responsabilidade terrível. ${ }^{37}$ (Tradução nossa)

Assim, a lógica da eleição, sugerida por Newbigin, não é uma lógica que concede exclusividade e privilégios a apenas um indivíduo ou povo, como foi o caso de Israel ou para a Igreja, segundo alguns - essa ideia é, de imediato, rejeitada pelo bispo de Madras. ${ }^{38}$ Pelo contrário, segundo Newbigin:

Para conhecermos Deus, para estarmos em comunhão com ele, somos dependentes daquele a quem ele nos dá como portador dessa relação, não apenas como um mestre e guia ao longo do caminho, mas como o parceiro no final. Não há, não pode haver, só particular, salvação que não nos envolve uns com os outros. Portanto, puder me arriscar a usar uma metáfora que usei em outro ponto, a revelação salvífica que Deus faz de si mesmo não vem diretamente do alto para nós aqui embaixo e tem pela claraboia, poderíamos dizer. Para recebermos a revelação salvífica de Deus, abrir a porta para o próximo a quem ele enviar como seu mensageiro designado, e - além do mais - receber esse mensageiro não como mestre o guia provisório a quem podemos dispensar quando nós mesmos tivermos aprendido que é necessário, mas como alguém com quem dividiremos permanentemente nosso lar. Não há salvação a não ser aquela na qual somos algo juntos por meio daquele a quem Deus envia como portador da sua salvação. ${ }^{39}$

Para ele, há uma "lógica da eleição" que não é a ideia comum que tanto defensores ou opositores dessa doutrina entendem. Newbigin entende que a salvação, em termos bíblicos, não está relacionada ao indivíduo como um ser autônomo e solitário. ${ }^{40}$ No seu entendimento, as Escrituras demonstram que, "desde o seu início, a Bíblia vê a vida humana em termos de relacionamento". ${ }^{41}$ Deste modo, a eleição consiste não no chamamento de indivíduos, mas de comunidades. Porém, não comunidades que devem se isolar e, assentadas num monte, esperar a destruição daqueles infelizes que não foram escolhidos (Jn 4,5). A eleição de um povo tem como razão e objetivo a salvação dos demais povos, como demonstra Newbigin:

\footnotetext{
${ }^{37}$ NEWBIGIN, L., The Open Secret, p.72-73.

${ }^{38}$ NEWBIGIN, L., O Evangelho em uma Sociedade Pluralista, p.116.

${ }^{39}$ NEWBIGIN, L., O Evangelho em uma Sociedade Pluralista, p. 114.

${ }^{40}$ NEWBIGIN, L., O Evangelho em uma Sociedade Pluralista, p. 114.

${ }^{41}$ NEWBIGIN, L., O Evangelho em uma Sociedade Pluralista, p. 114.
} 
Para conhecermos a Deus, para estarmos em comunhão com ele, somos dependentes daquele a quem ele nos envia como portador dessa relação, não apenas como um mestre e guia ao longo do caminho, mas como o parceiro no final. Não há, nem pode haver, salvação particular, a salvação que não nos envolve uns com os outros. Portanto, se eu puder me arriscar a usar uma metáfora que eu usei em outro ponto, a revelação salvífica que Deus faz de si mesmo não vem diretamente do alto para nós aqui embaixo - pela claraboia, como poderíamos dizer. Para recebermos a revelação salvífica de Deus, temos de abrir a porta para o próximo a quem ele enviar como mensageiro designando, - além do mais - receber esse mensageiro não como mestre ou guia provisório a quem podemos dispensar quando nós mesmos tivermos aprendido o que é necessário, mas como alguém com quem dividiremos permanentemente nosso lar. Não há salvação a não ser aquela na qual somos salvos juntos por meio daquele a quem Deus envia como portador da sua salvação. ${ }^{42}$

A experiência da salvação não é vista por Newbigin como algo que acontece no secreto do quarto (Mt 6,6). Pelo contrário, essa é uma experiência que acontece pela mediação de outros que já a tiveram. As seguidoras e seguidores de Jesus, enviados por ele para anunciar o Evangelho, são, para Lesslie Newbigin, portadores da salvação. Isso é esclarecido pelo autor da seguinte forma:

a. A Igreja, como corpo de Cristo, é entendida por Newbigin como representante de Jesus Cristo. Newbigin, observando as narrativas dos evangelhos, percebe o Nazareno investindo tempo em chamar, capacitar e enviar os seus discípulos ao mundo. ${ }^{43}$ Ele deixa claro, que Jesus não estava interessado em deixar um "código de conduta infalível", ${ }^{44}$ mas, sim, deixar uma comunidade que desse testemunho dele, assim como o próprio Jesus deu testemunho de seu Deus e Pai. ${ }^{45}$ Logo, Jesus é representado, na plenitude do seu poder, pelo povo a quem escolheu e comissionou. ${ }^{46}$ Desta forma,

A Igreja (é) apresentada como uma comunidade de homens e mulheres escolhidos e enviados. Pedro e André, Tiago e João não se apresentam como místicos à procura de uma verdade religiosa que teriam finalmente

\footnotetext{
${ }^{42}$ NEWBIGIN, L., O Evangelho em uma Sociedade Pluralista, p. 114.

${ }^{43}$ NEWBIGIN, L., La Familia de Dios, p. 85-86.

${ }^{44}$ NEWBIGIN, L., La Familia de Dios, p. 85.

${ }^{45}$ NEWBIGIN, L., La Familia de Dios, p. 86.

${ }^{46}$ NEWBIGIN, L., La Familia de Dios, p. 87.
} 
descoberto no ensino de Jesus. Aparecem como homens escolhidos por um líder para uma missão, para um trabalho ativo, ao invés de formar um grupo de estudos ou um clube religioso. É muito significativo constatar que, segundo s. Mateus, o grande sermão de Jesus foi dirigido aos homens que ele escolheu chamar. Não é o discurso de um mestre que procura atrair os que estão interessados em seus ensinamentos. Antes é uma convocação de tropas escolhidas sob as ordens de um oficial superior. ${ }^{47}$

Portanto, a primeira característica da Igreja, como Corpo de Cristo, tem a ver com a representatividade do seu Senhor. A Igreja não é chamada para fazer o anúncio ou publicidade de si mesma. Nem tampouco seu chamamento diz respeito à sua estrutura. Seu papel é ser representante vivo e presente de Jesus Cristo e de sua salvação.

b. A segunda característica da Lógica da Eleição é que a Igreja deve ser entendida como um povo pars pro toto, isto é, uma parte a favor do todo, ou mais especificamente, um "povo a favor dos outros povos". Como dito anteriormente, a doutrina da eleição causa grande dificuldade ao anúncio do Evangelho, porque, via de regra, ela é mal compreendida, como Newbigin procurou demonstrar. ${ }^{48}$ Comumente, entende-se que um povo escolhido é privilegiado por ser o único entre os demais. Porém, como também foi dito, muito mais que um privilégio há, na eleição, uma responsabilidade, porquanto "Deus executa seu propósito salvador por meio do chamamento de um povo, de uma tribo entre outras tribos do mundo" (1Pe 2,8-10). ${ }^{49}$ Não há, portanto, qualquer direito do povo eleito sobre a eleição divina. E Newbigin é incisivo em demonstrar isso:

A graça de Deus é gratuita e incondicional. Não podemos transformar a aliança da Graça num contrato. Ninguém, quem quer que seja, pode assegurar direitos a graça de Deus que excluam os outros. A graça eletiva de Deus cria um povo responsável por ser portador da salvação universal de Deus. Ele se compromete com esse povo. Porém, esse povo nunca pode estabelecer direitos sobre ele que exclui os outros. A graça de Deus é gratuita e a sua aliança não pode ser transformada num contrato. ${ }^{50}$

\footnotetext{
${ }^{47}$ NEWBIGIN, L., A Religião do Homem Secular, p. 161.

${ }^{48}$ NEWBIGIN, L., O Evangelho em uma Sociedade Pluralista, p. 116-118.

${ }^{49}$ NEWBIGIN, L., La Familia de Dios, p. 87-88.

${ }^{50}$ NEWBIGIN, L., O Evangelho em uma Sociedade Pluralista, p. 117.
} 
c. A solidariedade humana. Para Newbigin, ao criar o ser humano e todas as demais coisas, Deus fez com que o ser humano estivesse de tal modo vinculado a outro ser humano, que todas as esferas da vida se encontram vinculadas e a humanidade interligada em categorias corporativas. ${ }^{51}$ Portanto, o indivíduo é solidariamente responsável pelos seus iguais, de sorte que jamais poderá dizer, como Caim: "Acaso sou guarda do meu irmão"? (Gn 4,9). É, a partir dessa solidariedade, que a Igreja deve se responsabilizar pela evangelização, o anúncio do grande amor de Deus, posto que o Deus e Pai de Jesus Cristo "não trabalha somente com indivíduos isolados com responsabilidade por si mesmos, mas que ele trabalha em suas conexões naturais, como a família, o parentesco ou de toda uma nação". ${ }^{52}$ Desta forma, a Igreja ou mesmo o indivíduo precisam compreender que eles são pars pro toto, e não simplesmente a parte que importa. ${ }^{53}$ A solidariedade da Igreja para com o todo da criação é parte constitutiva de sua natureza missionária, a qual não pode ser negada, sob o risco de grave contradição ou mesmo de não-identificação como corpo de Cristo. Newbigin escreve:

A crença corrente dos cristãos, na maioria das igrejas, é de que a Igreja pode existir sem que ela seja missão, isso envolve uma contradição radical a verdade que constitui o que é ser Igreja. Não se pode resgatar a verdadeira plenitude da natureza da Igreja até que se recupere radicalmente o seu caráter missionário. ${ }^{54}$

d. A salvação é para todo o orbe criado. Para o bispo Newbigin, toda criação, em sua essência, é boa. ${ }^{55}$ Por outro lado, a criação, por conta do pecado humano, está sujeita a corrupção e, mesmo não sendo má, por isso, não pode ser considerada neutra. ${ }^{56} \mathrm{O}$ que Newbigin chama a atenção do seu leitor é para o fato de que toda a criação visível carece da redenção e da restauração apresentada por Jesus Cristo. Newbigin antecipa, em várias décadas, a fala do papa Francisco em sua encíclica Laudato Si' (LS), na qual expressa a necessidade do resgate da dimensão ecológica da fé cristã no cuidado da nossa casa

\footnotetext{
${ }^{51}$ NEWBIGIN, L., La Familia de Dios, p. 88-89.

${ }^{52}$ NEWBIGIN, L., La Familia de Dios, p. 90-91.

${ }^{53}$ NEWBIGIN, L., A Religião do Homem Secular, p. 113.

${ }^{54}$ NEWBIGIN, L., La Familia de Dios, p. 207.

${ }^{55}$ NEWBIGIN, L., La Familia de Dios, p. 90.

${ }^{56}$ NEWBIGIN, L., La Familia de Dios, p. 90.
} 
comum. ${ }^{57}$ Assim, como Newbigin, Francisco afirmou que "todas as criaturas do universo material encontram o seu verdadeiro sentido no Verbo encarnado, porque o Filho de Deus incorporou na sua pessoa parte do universo material, onde introduziu um gérmen de transformação definitiva" ${ }^{58}$. Portanto, o Reino de Deus não pode ser entendido como meramente espiritual, dentro de um dualismo de modelo platônico, mas ele está presente em e sobre todas as coisas pertencente à essa criação visível. Newbigin, portanto, entende que, na consumação final, quando tudo estiver sujeito à Deus, está incluído também "a renovação de todo o universo criado, do corpo do ser humano e a restauração da harmonia perdida na alegria do serviço à Deus", ${ }^{59}$ sendo essa a razão da existência de todo o orbe criado. ${ }^{60}$

Neste ponto, percebe-se que Newbigin está rompendo com uma longa e conhecida tradição presente no cristianismo, o dualismo, que diferentemente do proposto nas Sagradas Escrituras, no que diz respeito à teologia da criação e mesmo da antropologia: a confissão da existência de uma unidade essencial. ${ }^{61}$ A compreensão newbiginiana é que Deus fez o ser humano como uma unidade corpo e alma, e que qualquer tentativa de separar essas duas coisas, apenas conduziria ao desastre. ${ }^{62}$

Aplicando isso a dinâmica da Igreja, como Corpo de Cristo, pode-se destacar as seguintes consequências dessa percepção newbiginiana:

a. A Igreja não é uma realidade "espiritual", antes é uma comunidade visível e marcada por sinais visíveis, num mundo concreto;

b. Por conta disso, a Igreja se interessa por todas as dimensões da vida humana, mas também "pode saborear de antemão a restauração da criação à verdadeira harmonia em e para a glória de Deus, e do ser humano a verdadeira relação com o mundo criado". ${ }^{63}$

c. Por fim, a Igreja perceberá o mundo não como algo "entesourado para o fogo" da destruição, que ele será libertado da iniquidade e maldade

\footnotetext{
${ }^{57} \mathrm{LS}, 4$.

${ }^{58} \mathrm{LS}, 235$.

${ }^{59}$ NEWBIGIN, L., La Familia de Dios, p. 90.

${ }^{60}$ NEWBIGIN, L., La Familia de Dios, p. 90.

${ }^{61}$ DUSSEL, E., El Dualismo en la antropología cristiana, p. 14.

${ }^{62}$ NEWBIGIN, L., La Familia de Dios, p. 91.

${ }^{63}$ NEWBIGIN, L., La Familia de Dios, p. 91.
} 
humana (2Pe 3,7) ${ }^{64}$ Portanto, o mundo se torna alvo do amor da Igreja, assim como é alvo do amor de Deus.

O que pode ser apurado, então, é que a Igreja, enquanto corpo de Cristo e comunidade dos eleitos, não é um fim em si mesma, mas ela é pars pro toto da humanidade e de toda criação, fazendo verdadeira a conhecida afirmação de Dietrich Bonhoeffer: "a Igreja só é Igreja quando existe para outros". ${ }^{65}$ Ela é comunidade para as outras comunidades, ela é povo para outros povos. Com base nisso, é preciso considerar, agora, dois critérios que Newbigin destacou como fundamentais para se entender o que é a incorporação em Jesus Cristo, a saber: (a) a incorporação na Igreja é marcada sacramentalmente e (b) incorporação implica a participação.

A primeira implicação é que a Igreja, como corpo de Cristo, é uma comunidade visível, não apenas em sua presença no mundo, mas também pela forma da incorporação daqueles que creem. Os sacramentos, portanto, são essas marcas que dão visibilidade à "incorporação ao corpo de Cristo e a participação do Espírito". ${ }^{66}$ Newbigin está em franca oposição ao pensamento protestante, que enfatiza a fé sobre as formas visíveis da manifestação da Igreja. Isso está ligado à própria ideia da existência de uma Igreja Invisível e outra Visível, sendo a última sombra da primeira. Newbigin chama a atenção, principalmente dos protestantes, que na maior parte secundarizam os sacramentos. Contudo, Newbigin afirma que, em todo o Novo Testamento, a "admissão à nova aliança com todos os seus privilégios e responsabilidades se dava por meio da fé e do batismo". ${ }^{67}$ De acordo com Newbigin "ser batizado é ser incorporado à morte de Jesus de modo a tornar-se participante da sua vida ressurreta e, assim, compartilhar sua missão contínua ao mundo. É ser batizado na sua missão" ${ }^{68}$

A segunda implicação da incorporação à Igreja, exige a participação daquele que, sacramentalmente, foi admitido tanto na morte e como na vida ressurreta de Jesus Cristo. ${ }^{69}$ A Eucaristia ou Ceia do Senhor teria, na concepção de Newbigin, o papel de marcar a participação do cristão na vida ressurreta de

\footnotetext{
${ }^{64}$ De acordo com Charles Biggs, o escritor petrino não está interessado em dizer o que é o fogo, mas o que ele fará, isto é, o julgamento da maldade humana. BIGGS, C., A Critical and Exegetical Commentary on the Epistles of St Peter and St Jude, p. 294-295.

${ }^{65}$ BONHOEFFER, D., Resistência e Submissão, p. 186.

${ }^{66}$ NEWBIGIN, L., La Familia de Dios, p. 93.

${ }^{67}$ NEWBIGIN, L., La Familia de Dios, p. 92.

${ }^{68}$ NEWBIGIN, L., O Evangelho em uma Sociedade Pluralista, p. 157.

${ }^{69}$ NEWBIGIN, L., La Familia de Dios, p. 95.
} 
Jesus e tornar o centro da interdependência dos membros do corpo de Cristo. ${ }^{70}$ Os sacramentos não devem apenas unir, incorporar os que creem ao corpo de Cristo, que é a Igreja, mas, como visto, estende sua função para além disso. Sinaliza o envolvimento vital da participação e ação da Igreja em seu ministério continuador, na missão dada pelo Ressuscitado, uma vez que por eles, anuncia-se "a morte [e ressurreição] do Senhor até que ele venha" (1Cor 11,26).

\title{
5. Igreja como comunidade do Espírito Santo
}

Por fim, a terceira característica da natureza da Igreja, segundo Newbigin, é pneumatológica, de modo que ela é a comunidade do Espírito Santo. ${ }^{71}$ Assim, Newbigin, chama a atenção tanto de protestantes como de católicos para as suas respectivas formas de entender a natureza da Igreja de Cristo, ${ }^{72}$ acrescentando um terceiro elemento que, segundo ele, foi de alguma maneira deixada de lado por essas duas tradições do cristianismo ocidental. ${ }^{73}$ Newbigin denomina essa tradição de Pentecostal, uma indicação clara que o terceiro elemento para se compreender a natureza da Igreja é o Espírito Santo, já que os crentes são "incorporados (à Igreja) por receber e permanecer no Espírito Santo". ${ }^{74}$ Sobre a relação do Espírito com a Igreja, Newbigin escreve:

\begin{abstract}
Quando o Senhor Ressuscitado deu a comissão apostólica para a Igreja, deu-lhe também o poder para continuar a sua missão, o coração desse ato, mediante o qual foi concedido esse poder, é o Espírito Santo: "Disse-lhes, pois, Jesus outra vez: Paz seja convosco! Assim como o Pai me enviou, eu também vos envio. E, havendo dito isto, soprou sobre eles e disselhes: Recebei o Espírito Santo. Se de alguns perdoardes os pecados, são-lhes perdoados; se lhos retiverdes, são retidos" (Jo 20,21-23 ARA). O comissionamento é ungido pelo Espírito e os comissionados também são ungidos de maneira singular. Também o mandato de ser suas testemunhas está inseparavelmente conectado com o dom do Espírito Santo: "recebereis
\end{abstract}

\footnotetext{
${ }^{70}$ NEWBIGIN, L., La Familia de Dios, p. 99-100.

${ }^{71}$ A tradução espanhola que está sendo utilizada neste artigo traduz "Community", por comunhão, por certo, porque no texto Newbigin usa o termo grego koinonia. Porém, admite-se que o termo comunidade oferece um sentido de agrupamento que pertence ao Espírito, o sentido que Newbigin pretendia.

${ }^{72}$ NEWBIGIN, L., La Familia de Dios, p. 121.

${ }^{73}$ NEWBIGIN, L., La Familia de Dios, p. 132.

${ }^{74}$ NEWBIGIN, L., La Familia de Dios, p. 42.
} 
poder ao descer sobre vós o Espírito Santo, e sereis minhas testemunhas" (At 1,8 ARA). Como temos visto, o próprio Espírito Santo é a testemunha primordial e essencial. E unicamente a sua presença faz com que os discípulos, de fato, sejam testemunhas dele. ${ }^{75}$ (Tradução nossa)

Para Newbigin, qualquer eclesiologia que não tenha esse caráter pneumatológico, que também a torna trinitária, perde o sentido, porque é o Espírito Santo que dá sentido tanto à continuação da missão apostólica como ao testemunho da fé. Porquanto, a Igreja "não vive por sua fidelidade a mensagem, nem por manter a comunhão direta com os apóstolos, porém, vive por meio do poder supremo do Espírito de Deus", afirma Newbigin ${ }^{76}$

Nessa dimensão do Espírito, a Igreja é empoderada para a missão. Deus deseja recriar toda a raça humana à imagem do Filho ( $R m$ 8,28-29). No evangelho proclamado por Jesus, a humanidade toma conhecimento desse desejo amoroso de Deus Pai. Em todos os eventos da vida, ministério, morte e ressurreição do Senhor, vê-se em palavras e gestos todo o amor do Pai. Uma nova possibilidade de vida está aberta à humanidade, um Reino que não é deste mundo, porque é radicalmente diferente, pois nele não se conhece o mal, nem tampouco se abriga o ódio (Jo 18,36). Este é o Reino do amor, justiça, paz e alegria de Deus $(\mathrm{Rm} 14,17)$, que é antecipadamente desfrutado pela Igreja na experiência da presença do Espírito Santo.

Por isso mesmo, essa não é uma notícia para ser deixada no silêncio. ${ }^{77}$ Assim, como a mensagem dos anjos aos pastores dos arredores de Belém, essa é uma boa-notícia de grande alegria, não apenas para todo o povo, mas para todos os povos (Lc 2,11). A missão do Espírito Santo, como visto, é trazer o antegozo do Reino, mas também habilitar a Igreja no cumprimento na missão apostólica. $\mathrm{O}$ envio à todas as nações. ${ }^{78}$ É pelo seu agir em sua comunidade, em que todos comumente participam dos dons trazidos pelo Espírito, que o mesmo Espírito edifica em amor e provê o amor, e tudo o que é necessário para o prosseguimento a missão de Jesus. ${ }^{79} \mathrm{Com}$ a presença do Espírito Santo que a missão de Jesus é continuada pela Igreja na mesma dinâmica e poder. ${ }^{80}$

\footnotetext{
${ }^{75}$ NEWBIGIN, L., La Familia de Dios, p. 132-133.

${ }^{76}$ NEWBIGIN, L., La Familia de Dios, p. 133.

${ }^{77}$ NEWBIGIN, L., O Evangelho em uma Sociedade Pluralista, p. 155.

${ }^{78}$ NEWBIGIN, L., La Familia de Dios, p. 143.

${ }^{79}$ NEWBIGIN, L., La Familia de Dios, p.143-144.

${ }^{80}$ É importante considerar aqui há possibilidade de diálogo entre a teo-missiologia trinitária de
} 


\section{Conclusão}

Tendo observado neste trabalho, os principais aspectos da proposta eclesiológica feita por Lesslie Newbigin, tendo como ponto de partida o seu entendimento, que foi denominado de missio trinitatis Dei, é possível pontuar algumas implicações:

a. O interesse do Deus Uno e Trino pelo mundo. Algo que fica claro na exposição de Newbigin da Trindade como fundamento e chave-de-interpretação de sua teologia missiológica é o interesse de Deus pelo mundo. $\mathrm{O}$ amor de Deus está voltado para a humanidade em sua totalidade, mas também está interessado naquilo que a humanidade tem desenvolvido social e culturalmente. Na variedade das interpretações do termo kosmos, no contexto joanino, o foco está no ser humano e em suas construções diante dos Mandatos Criacionais, ${ }^{81}$ conquanto, o mundo também pode ser visto como uma ordem visível de oposição contra Deus, de modo que a presença de Jesus é um confronto.$^{82}$ Confronto que, aliás, Deus esteve e está interessado, porque é por meio deste conflito, que o seu amor é demonstrado para a salvação de todo aquele que crê.

Sendo assim, a Igreja deve compartilhar o mesmo objeto do amor de Deus, isto é, o mundo. O que não significa pactuar-se com o pecado e a maldade - Jesus jamais se envolveu com tais coisas, embora, tenha estado ao lado de pecadores. Isso conduz a uma segunda implicação.

b. Superação do dualismo Igreja-Mundo. ${ }^{83}$ Se Newbigin supera o dualismo, por que falar em uma relação entre a Igreja e o Mundo? Não estaria essa relação desenvolvendo uma chave interpretativa de opo-

Lesslie Newbigin com a teologia de Jürgen Moltmann, muito mais conhecida do público, principalmente aquela apresentada em Trindade e Reino de Deus, de 1981. Entretanto, a proposta deste trabalho não permite esse diálogo.

${ }^{81}$ HENDRIKSEN, W., João, p. 192.

${ }^{82}$ NEWBIGIN, L., The Light has come, p. 43

${ }^{83}$ É preciso lembrar que toda a construção do pensamento de Newbigin e mesmo de Comblin neste capítulo não é exaustivo. $\mathrm{O}$ exame de ambos os modelos teológicos tem como finalidade estabelecer o modo como cada um compreende a relação Igreja-Mundo, afim de que possam ser analisados e avaliados os processos evangelizadores da IP-ST. De modo mais amplo, aos interessados em compreender o pensamento eclesiológico de Newbigin, recomenda-se a leitura de: NEWBIGIN, L., The Household of God; NEWBIGIN, L., One Body, One Gospel, One World; NICOLAJSEN, J. B., The Distinctive Identity of the Church. 
sição-exclusão? O que Newbigin tem a dizer sobre isso? Para responder essa e outras possíveis questões que podem derivar destas, faz-se necessário compreender o conceito que Newbigin desenvolve em sua teologia da eleição.

Nesta superação do dualismo reinante tanto na cosmovisão contemporânea como na cosmovisão cristã, Newbigin também procura reintegrar uma dicotomia feita pelo protestantismo em meados do século XVIII, a separação entre Igreja e Missão. Nicolajsen explica que no início do século XX, a ideia comum era que Igreja era a instituição que congregava e fazia a manutenção dos crentes, além de dar suporte a Missão; enquanto a Missão tinha a tarefa de proclamar o evangelho as nações estrangeiras não-cristãs. ${ }^{84}$ Para Newbigin, foi o próprio contato missionário com outros povos e culturas que tornou necessária a reflexão sobre acerca da relação da Igreja com o mundo, o que por sua vez implicava também na reflexão sobre a própria natureza da Igreja ${ }^{85}$ isto é, sua natureza missional.

A Igreja, como o seu Senhor, tem um propósito. Não se trata de algo novo, mas de uma continuidade de propósito, que vem a ser tão-somente a salvação daquele que se perdeu. Newbigin afirmou:

Na sua jornada ao longo da história, a igreja terá, portanto, esse caráter duplo na medida em que for fiel à sua comissão. Por um lado, ela será uma igreja sofredora, porque os poderes das trevas, embora frustrados e privados da autoridade final, ainda são poderosos. Assim como Jesus nos ama conseguindo desmascarar a potestade e desse modo atribuiu a utilidade delas sobre si mesmo trabalhando por meio da vida e do testemunho da Igreja Missionária, derrubar a mais fundamental das crenças do mundo, provando que o mundo está errado em relação ao pecado a justiça e ao juízo (Jo 16,8). Consequentemente, o mundo odiará a igreja como odiava o senhor dela. Mas, por outro lado, assim como o ministério de Jesus foi

\footnotetext{
${ }^{84}$ NICOLAJSEN, J. B., The Distinctive Identity of the Church, p. 24. Um exemplo desta distinção ocorreu no seio da Igreja Presbiteriana do Brasil (IPB). Sendo a igreja ligado ao protestantismo missionário, conforme categorias de Mendonça, a grande maioria dos pastores dessa denominação era composta por missionários norte-americanos. Em 1903, houve uma proposta de desvincular a igreja e a missão. De modo que, assim que os missionários tivessem plantado uma igreja, que estivesse com condições de se autossustentar, essa comunidade deixaria de pertencer às missões e seria integrada a IPB. Essa compreensão dicotômica, missão -igreja, gerou animosidade na assembleia geral daquele ano, sendo uma das causas do primeiro cisma presbiteriano no Brasil. FERREIRA, J. A., História da Igreja Presbiteriana, p.426-433.

${ }^{85}$ NEWBIGIN, L., La Familia de Dios, p. 19.
} 
marcado por grandes obras que para com aqueles olhos para ver e ouvidos para ouvir era os sinais da presença do Reino de Deus com poder, vida da igreja a ver as grandes obras com a mesma função. Elas não são - por assim dizer - passos no caminho para o reino, mas revelações, vislumbres desse reino que já é uma realidade, mas uma realidade conhecida somente por aqueles que se converteram, dominaram os falsos deuses e se voltaram para o Deus vivo. ${ }^{86}$

É básico para qualquer um que esteja engajado com a evangelização a noção que o Evangelho é o poder de Deus para a salvação. Diante disso, diz Newbigin, que a "Igreja é um movimento lançado na vida do mundo para levar, em sua própria vida, a dádiva da paz de Deus para a vida do mundo". ${ }^{87}$ A Igreja, no cumprimento da missão, aprende seu lugar e função; entende que ela não se basta, mas que tem um compromisso a ser cumprido para o bem do mundo. A Igreja se percebe como comunidade para o mundo.

\section{Referências bibliográficas}

BÍBLIA SAGRADA. Almeida Revista e Atualizada, 2.ed. Barueri: Sociedade Bíblica do Brasil, 1999.

BIGGS, C. A Critical and Exegetical Commentary on the Epistles of St Peter and St Jude. New York: Charles Scribner's Sons, 1901.

BLAUW, J. A Natureza Missionária da Igreja. São Paulo: ASTE, 1966.

BONHOEFFER, D. Resistência e Submissão. Rio de Janeiro: Paz \& Terra; São Leopoldo: Sinodal, 1980.

BOSCH, D. Missão Transformadora, 4.ed. São Leopoldo: Sinodal, 2002.

BOSCH, D. J. Transforming Mission: Paradigm Shifts in Theology of Mission - American Society of Missiology Series, n.16. New York: Orbis Book, 1991.

CONCÍLIO VATICANO II. Decreto Ad Gentes sobre a atividade missionária da Igreja. In: Documentos do Concílio Vaticano II. São Paulo: Paulus, 2001.

CONFISSÃO de Fé de Westminster. São Paulo: Cultura Cristã, 2001.

COX, H. A Cidade do Homem. Rio de Janeiro: Paz e Terra, 1968.

CUNHA, G. NÃO OS TIRES DO MUNDO: Estudo da relação Igreja-Mun-

${ }^{86}$ NEWBIGIN, L., La Familia de Dios, p. 144.

${ }^{87}$ NEWBIGIN, L., The Open Secret, p. 48-49 
do numa denominação presbiteriana brasileira, à luz da reflexão teológica de Lesslie Newbigin e José Comblin. Rio de Janeiro, 2019. 524p. Tese. Faculdade de Teologia, Pontifícia Universidade Católica do Rio de Janeiro. Disponível em: <https://www.maxwell.vrac.puc-rio.br/47084/47084.PDF>. Acesso em: 5 fev. 2021.

DIXHOORN, C. Guia de Estudo Confissão de Fé de Westminster. São Paulo: Cultura Cristã, 2017.

DUSSEL, E. EI Dualismo en la antropología cristiana. Buenos Aires: Editorial Guadalupe, 1974.

FERREIRA, J. A. História da Igreja Presbiteriana. São Paulo: Cultura Cristã, 1990.

GOHEEN, M. W. As the Father Has Sent Me, I Am Sending You: J. E. Lesslie Newbigin's Missionary Ecclesiology. 2000. Utrecht, 2000. 483p. Tese. Interuniversitair Instituut voor Missiologie en Oecumenica. Universidade de Utrecht (Holanda).

GRUDEM, W. Teologia Sistemática. São Paulo: Vida Nova, 1999.

HENDRIKSEN, W. João. São Paulo: Cultura Cristã, 2004.

IGREJA CATÓLICA APOSTÓLICA ROMANA; FEDERAÇÃO LUTERANA MUNDIAL. Declaração conjunta sobre a Doutrina da Justificação. Disponível em: <http://www.vatican.va/roman_curia/pontifical_councils/ chrstuni/documents/rc_pc_chrstuni_doc_31101999_cath-luth-joint-decla ration_po.html $>$. Acesso em: 19 ago. 2018.

MOSLEY, A. Kingsmead 1969-77: Preparing for Mission Overseas. Disponível em: <http://www.methodistheritage.org.uk/missionary-history-mosley -kingsmead-2004.pdf>. Acesso em: 12 set. 2018.

NEWBIGIN, L. A Religião do Homem Secular. São Paulo: Paulinas, 1969.

NEWBIGIN, L. La Familia de Dios. Ciudad de México: Casa Unida de Publicaciones, 1961.

NEWBIGIN, L. O Evangelho em uma Sociedade Pluralista. Viçosa: Ultimato, 2016.

NEWBIGIN, L. One Body, One Gospel, One World. London: International Missionary Council, 1958.

NEWBIGIN, L. The Household of God. New York: Friendship Press, 1954.

NEWBIGIN, L. The Light has come: An exposition of the Fourth Gospel. Grand Rapids: Eerdmans, 1982.

NEWBIGIN, L. The Mission of the Triune God. In: NEWBIGIN RE- 
SOURCES. Disponível em: <https://newbiginresources.org/1962-the-mission-of-the-triune-god/>. Acesso em: 21 jun. 2018.

NEWBIGIN, L. The Open Secret. Grand Rapids: Eedmans, 1978.

NICOLAJSEN, J. B. Beyond Sectarianism: The Missional Church in a Post-Christendom Society. In: Exchange: Journal of Contemporary Christianities in Context, v.41, n.4, p.364-380, January. 2012.

NICOLAJSEN, J. B. Missional ekklesiologi. En teologihistorisk analyse af en ekklesiolo-gisk tradition. Norwegian Journal for Missiotogy, v.63, n.1, p. 19-34, 2009 Disponível em: <https://journals.mf.no/ntm/article/ view/4205/3522>. Acesso em: 5 jul. 2018.

NICOLAJSEN, J. B. The Distinctive Identity of the Church: A Constructive Study of the Post-Christendom Theologies of Lesslie Newbigin and John Howard Yoder. Eugene: Pickwick Publications, 2014. (Edição do Kindle).

O'CONNOR, Daniel. All change at Selly Oak, CHURCH TIMES, 02 nov. 2006. Disponível em: <https://www.churchtimes.co.uk/articles/2005/30september/features/all-change-at-selly-oak>. Acesso em: 12 set. 2018.

STRONG, A. H. Teologia Sistemática. São Paulo: Hagnos, 2001. v.2.

VANDERVELDE, G. The Church as Missionary Community: The Church as Central Disclosure Point of the Kingdom. (Unpublished Paper). In: NICOLAJSEN, J. B. The Distinctive Identity of the Church: A Constructive Study of the Post-Christendom Theologies of Lesslie Newbigin and John Howard Yoder. Eugene: Pickwick Publications, 2014. [Edição do Kindle].

WAINWRIGHT, G. Lesslie Newbigin: A Theological Life. New York: Oxford Press, 2000.

Gladson Pereira da Cunha Doutor em Teologia Sistemático-Pastoral pela Pontifícia Universidade Católica do Rio de Janeiro Docente do Centro de Ensino Superior Fabra Serra / ES - Brasil E-mail: gladsoncunha@gmail.com

Recebido em: 19/08/2020 Aprovado em: 03/03/2021 